This item was submitted to Loughborough's Research Repository by the author.

Items in Figshare are protected by copyright, with all rights reserved, unless otherwise indicated.

\title{
Effect of microstructure on anomalous strain-rate-dependent behaviour of bacterial cellulose hydrogel
}

PLEASE CITE THE PUBLISHED VERSION

http://dx.doi.org/10.1016/j.msec.2016.01.042

\section{PUBLISHER}

(C) Elsevier

VERSION

AM (Accepted Manuscript)

\section{PUBLISHER STATEMENT}

This work is made available according to the conditions of the Creative Commons Attribution-NonCommercialNoDerivatives 4.0 International (CC BY-NC-ND 4.0) licence. Full details of this licence are available at: https://creativecommons.org/licenses/by-nc-nd/4.0/

\section{LICENCE}

CC BY-NC-ND 4.0

\section{REPOSITORY RECORD}

Gao, Xing, Zhijun Shi, Andrew Ka-Chun Lau, Changqing Liu, Guang Yang, and Vadim V. Silberschmidt. 2019. "Effect of Microstructure on Anomalous Strain-rate-dependent Behaviour of Bacterial Cellulose Hydrogel". figshare. https://hdl.handle.net/2134/20488. 


\title{
Effect of microstructure on anomalous strain- rate-dependent behaviour of bacterial cellulose hydrogel
}

\author{
Xing Gao ${ }^{1^{*}}$, Zhijun Shi ${ }^{{ }^{*}}$, Andrew Lau ${ }^{1}$, Changqin Liu ${ }^{1}$, Guang Yang ${ }^{2}$ and Vadim V. \\ Silberschmidt ${ }^{1}$ \\ ${ }^{1}$ Wolfson School of Mechanical and Manufacturing Engineering, Loughborough University, \\ Loughborough, UK \\ ${ }^{2}$ College of Life Science and Technology, Huazhong University of Science and Technology, \\ Wuhan, China
}

\begin{abstract}
This study is focused on anomalous strain-rate-dependent behaviour of bacterial cellulose (BC) hydrogel that can be strain-rate insensitive, hardening, softening, or strain-rate insensitive in various ranges of strain rate. $\mathrm{BC}$ hydrogel consists of randomly distributed nanofibres and a large content of free water; thanks to its ideal biocompatibility, it is suitable for biomedical applications. Motivated by its potential applications in complex loading conditions of body environment, its time-dependent behaviour was studied by means of inaqua uniaxial tension tests at constant temperature of $37^{\circ} \mathrm{C}$ at various strain rates ranging from $0.0001 \mathrm{~s}^{-1}$ to $0.3 \mathrm{~s}^{-1}$. Experimental results reflect anomalous strain-rate-dependent behaviour that was not documented before. Micro-morphological observations allowed identification of deformation mechanisms at low and high strain rates in relation to microstructural changes. Unlike strain-rate softening behaviours in other materials, reorientation of nanofibres and kinematics of free-water flow dominate the softening behaviour of BC hydrogel at high strain rates.
\end{abstract}

Key words: strain-rate softening; deformation mechanisms; microstructural changes; in-aqua testing; bacterial cellulose hydrogel

\section{Introduction}

Bacterial cellulose (BC) hydrogel is a product of primary metabolism of some bacteria (e.g. Acetobacter, Rhizobium, Agrobacteriumand and Sarcina). Individual bacteria synthesize long nanofibres that are randomly distributed and naturally interweaved in fibrous layers with a small fraction of nanofibres acting as cross-links in a multi-layer structure capable to hold a large content of free water ( $99 \mathrm{vol} \%$ ) in a space between fibrous layers, as a result, forming a hydrogel (Fig. 1). A growing interest to BC hydrogels is mainly thanks to their ideal

\footnotetext{
"Both XG and ZS have equal contributions to the paper and are co-first authors
} 
biocompatibility [1], making it a biomaterial suitable for various applications, such as components for wound dressing [2, 3], drug-delivery systems [4], etc. Recently, their applications in biomedical science attracted an increasing attention, such as artificial blood vessels $[5,6]$, regeneration of damaged peripheral nerves [7], implant tissues for ear-cartilage replacement [8], etc. Their microstructure with high porosity demonstrates a great potential for polymerization of chemical monomers and regeneration of tissues; as a result, BC-based composites [9, 10] and scaffolding for tissue engineering [11] developed rapidly in recent years.

$\mathrm{BC}$ nanofibre with stiffness of dozens of GPa $[12,13]$ higher than that of collagen fibres and matrix can provide mechanical reinforcement acting as the main load-bearing component [14]. Since it is non-biodegradable in-vivo, mechanical properties of the BC hydrogel will remain consistent with those of native tissues [8], enhancing the importance of comprehensive understanding of mechanical behaviour of $\mathrm{BC}$ under relevant conditions that is not fully investigated. As found in some recent studies, the BC hydrogel demonstrates nonlinear inelastic behaviour with unique deformation mechanisms [15]. Formation of entanglements and re-orientation of nanofibres by external loading dominate its mechanical performance in a quasi-static loading regime [15]. Squeezing of free water is one of key phenomena caused by shrinkage of a multi-layer network [16]. Since the BC hydrogel consists of solid and liquid phases, it demonstrates time-dependent behaviour thanks to the contribution of water. Considering its potential applications, it is essential to determine viscoelastic properties as well as time-dependent behaviour [17]. In a study of Nimeskern et al. [8], stress-relaxation indentation was performed to characterize viscoelastic properties of the $\mathrm{BC}$ with various cellulose contents for evaluation of potential use for ear-cartilage replacement. In-plane creep tests at various stress levels were carried out to determined viscoelastic properties of a BC hydrogel in terms of a fractional-exponential formulism [18].

Strain-rate-dependent feature is a typical property of time dependence of various materials. The effect of temperature and strain rate on material's performances is widely studied, both theoretically and experimentally, owing to thermal softening and viscous properties, respectively [19]. A typical behaviour of thermal-softening and strain-rate-dependent hardening is well documented [20, 21, 22], with strain-rate softening of amorphous polymers at large deformations and high strain rates reported, as a result of quasi-adiabatic heating leading to thermal softening [23]. Some studies were focused on strain-rate behaviour of BC hydrogels; as an example, out-of-plane compressive response of $\mathrm{BC}$ hydrogel at various strain rates was studied by Lopez-Sanchez et al. [24], showing the effect of water motion in the process of compression. Still, to the best of authors' knowledge, its in-plane strain-ratedependent behaviour has not been fully determined.

In this study, in-aqua uniaxial tensile tests were performed accompanied by micromorphological observations to characterize the in-plane strain-rate-dependent behaviour of $\mathrm{BC}$ hydrogel and to study its deformation mechanisms. Results demonstrate anomalous strain-rate-dependent behaviour at constant temperature of $37^{\circ} \mathrm{C}$ with a transition from hardening to softening with an increase in strain rate. Different from other softening 
mechanisms, here, reorientation of nanofibres and kinematics of free-water flow play a dominant role in softening behaviour at high strain rates.

\section{Material and methods}

\subsection{Materials}

A yeast extract and peptone (analytical reagent) were obtained from Oxoid Ltd, United Kingdom. Sodium hydroxide, disodium phosphate and citric acid (analytical reagent) were obtained from Sinopharm Chemical Reagent Co. Ltd., China. Glucose (edible grade) was obtained from Shangdong Xiwang Sugar Co. Ltd., China.

\subsection{Synthesis of bacterial cellulose hydrogel}

Gluconacetobacter xylinum (ATCC53582) was used for bio-synthesis of BC hydrogel. The bacterium was cultured in a Hestrin and Schramm (HS) medium, which was composed of $2 \%$ (weight) glucose, $0.5 \%$ (weight) yeast extract, $0.5 \%$ (weight) peptone, $0.27 \%$ (weight) disodium phosphate and $0.15 \%$ (weight) citric acid. After incubating statically for 7 days at $30^{\circ} \mathrm{C}$, and achieving the thickness of $\mathrm{BC}$ hydrogel in the range approximately from $3 \mathrm{~mm}$ to 5 $\mathrm{mm}$, samples of the $\mathrm{BC}$ hydrogel were dipped into deionized (DI) water for 2 days, and then steamed by boiling in a $1 \%$ (weight) $\mathrm{NaOH}$ solution for 30 mins to eliminating bacteria and proteins. Afterwards, the BC hydrogels (Fig. 1a) were purified by washing in DI water until its $\mathrm{pH}$ value approached 7 , and then were stored in DI water at $4^{\circ} \mathrm{C}$.
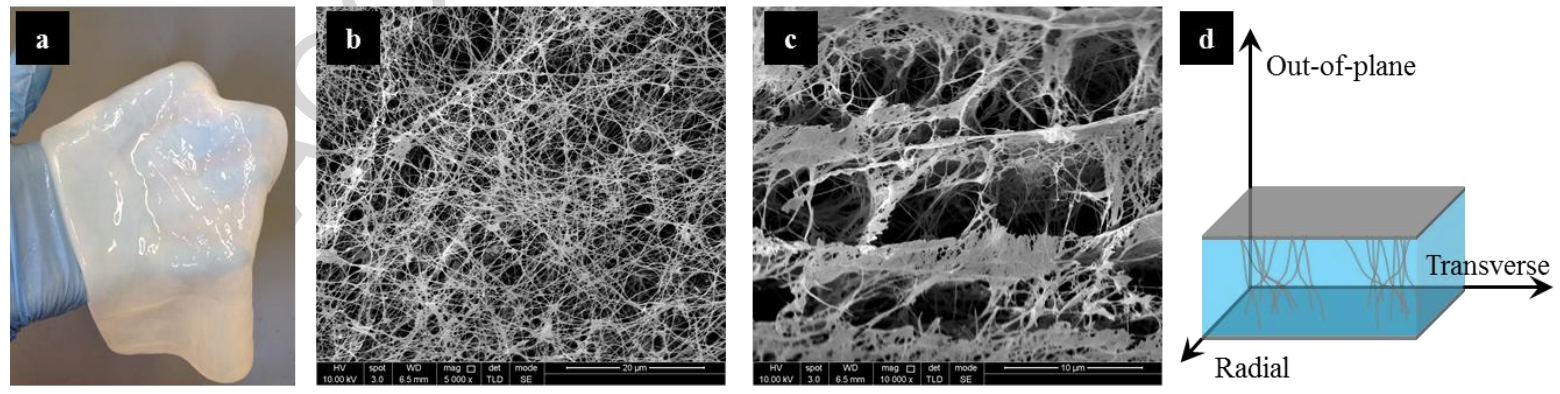

Figure 1: (a) Sheet of $100 \%$ hydrated BC hydrogel. In natural state, BC nanofibres are randomly distributed in a radial-transverse plane, forming fibrous layers (b) with some weak links (c) between them along the out-of-plane direction. (d) Schematic diagram of radial, transverse and out-of-plane directions.

\subsection{Sample preparation}

A wet BC hydrogel sheet was frozen before sample-cutting in order to keep its freshness and avoid pollution resulting from bacteria and fungi. Then, the sheet was stored in DI water at 
room temperature for half day before cutting. The BC hydrogel sheet was cut into dog-boneshape specimens by using a custom die based on dimensions suggested from ASTM D638-10 standard [25]. A compression machine provided impact loading for sample cutting to ensure uniform boundary without secondary damage to specimens. Then, because of the floppy texture of the BC hydrogel, specimens were stored in DI water for 2 hours to minimize the effect of cutting on the edges of specimens. Thickness of specimens was measured with callipers with accuracy of $\pm 0.01 \mathrm{~mm}$.

\subsection{Uniaxial tensile test}

Considering potential biomedical applicationsof the hydrogel, specimens were tested in aqua, at constant temperature of $37.0 \pm 1.0^{\circ} \mathrm{C}$ using a Bio-Puls system (Instron 3130-100 BioPuls Bath, Instron, USA). Pneumatic grips with water-proof sand paper were used to clamp specimens to prevent slippage during testing. Force was measured with a $100-\mathrm{N}$ load cell (2530 Series Low-profile Static Load Cell, Instron, USA), and the deformation was represented by crosshead displacement. A pre-load of $0.05 \mathrm{~N}$ was applied to ensure that the specimens were fully loaded at the beginning of testing. Specimens $(n=5)$ were subjected to uniaxial tension under a wide range of strain rates: $0.0001 \mathrm{~s}^{-1}, 0.00033 \mathrm{~s}^{-1}, 0.001 \mathrm{~s}^{-1}, 0.0033 \mathrm{~s}^{-}$ ${ }^{1}, 0.01 \mathrm{~s}^{-1}, 0.033 \mathrm{~s}^{-1}, 0.1 \mathrm{~s}^{-1}$ and $0.3 \mathrm{~s}^{-1}$, with the highest strain rate being a 3000 -fold of the initial strain rate. Two high-resolution digital cameras were set perpendicular to each other to record the geometric changes of specimens during testing.

\subsection{Micro-morphological observation}

Due to the size of $\mathrm{BC}$ nanofibres, electronic microscopy is necessary for micromorphological observations rather than optical microscopy, while the large water content and in-aqua testing environment contradicts to the basic requirement in SEM analysis - vacuum conditions. Hence, the real-time study of microstructural changes in the process of in-aqua testing is technically very challenging. Hence, the induced microstructure was used to observe microstructural changes. For this, specimens were stretched to $40 \%$ strain, and then fixed in a custom-made fixture [15]. Then, water in specimens was removed in a freeze-dryer. Micro-morphology of specimens was observed with emission-gun scanning electron microscopy.

\section{Results}

\subsection{Uniaxial tension at various strain rates}

Due to the Poisson's effect, a cross-sectional area of a stretched specimen shrinks under large deformations. The digital cameras recorded the process, demonstrating a phenomenon that at 
high strain rate the thinning of specimen is less than that at low and medium strain rates, reflecting that some processes proceeded differently at high strain rate, see the marked red areas at low, medium and high strain rates in Fig. 2.
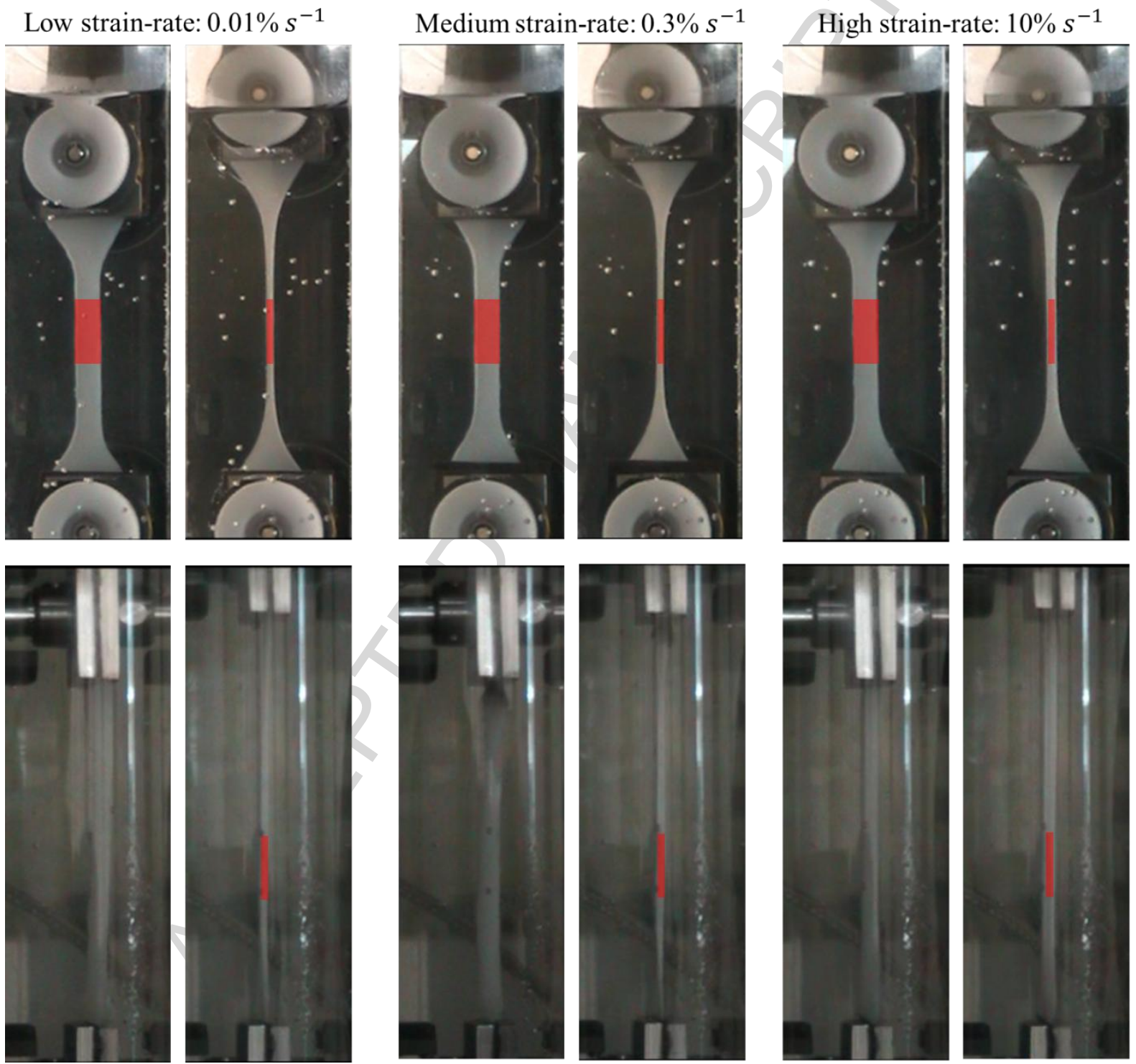

Figure 2: Geometric changes of specimens stretched at low, medium and high strain rates

The stress-strain curves up to 50\% strain are shown in Fig. 3a for each strain rate used in experiments. The error bars are not shown in this figure since some curves are overlapping, and this might lead to misunderstanding. It is evident that wet $\mathrm{BC}$ hydrogel demonstrated non-linear elastic behaviour under quasi-static tensile loading at each strain rate. The evolution of tangent modulus $E$, representing the stiffness of material at each data point, with strain exhibits the extent of non-linearity, as shown in Fig. 3b. Based on the evolution of tangent modulus at $0.0033 \mathrm{~s}^{-1}$ (curve 4 in Fig. 3b), behaviour under uniaxial tension could be 
typically divided into four characteristic stages: 1 - initial quasi-linear stage $\left(S_{1}\right) ; 2$ nonlinear stage $\left(S_{2}\right) ; 3$ - linear stage $\left(S_{3}\right) ; 4$ - pre-failure stage $\left(S_{4}\right)$.
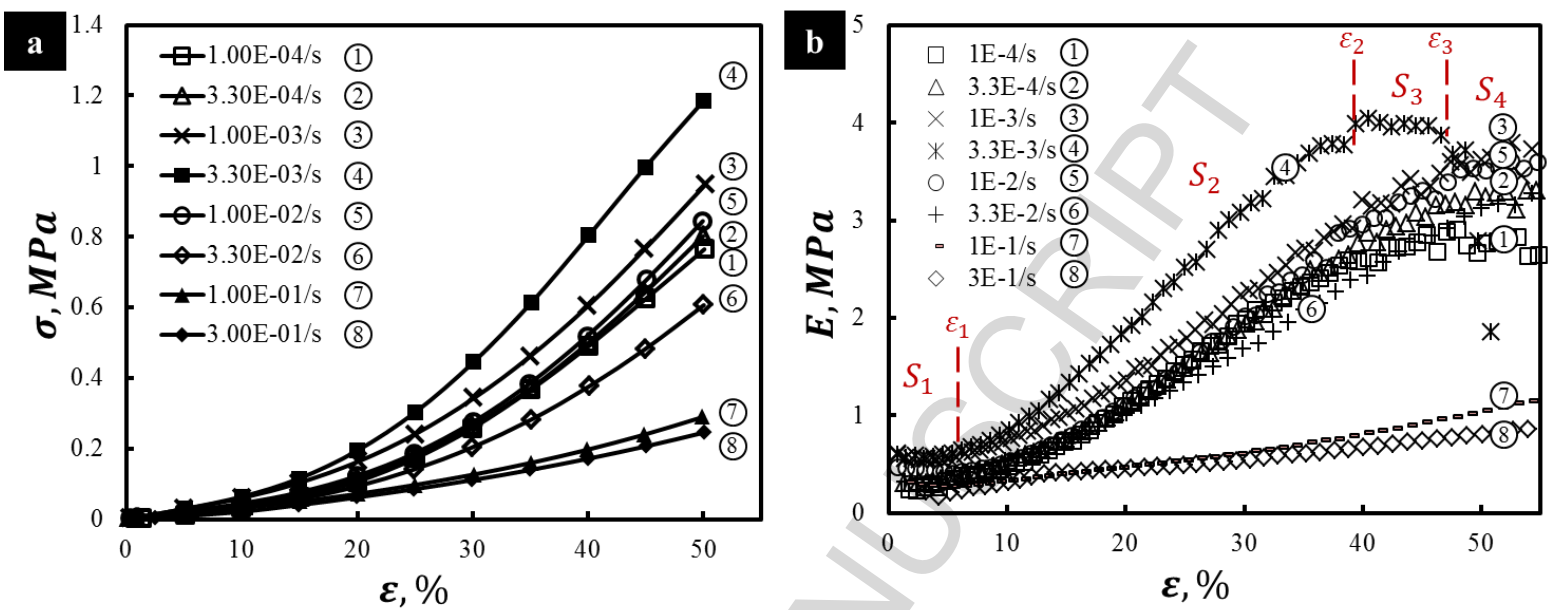

Figure 3: (a) Averaged stress-strain curves of $\mathrm{BC}$ hydrogel at various strain rates under uniaxial tension loading; (b) evolution of tangent modulus with strain at various strain rates

To understand this strain-rate-dependent behaviour, it is essential to measure various parameters for these characteristic stages. The dependence of initial modulus $E_{1}$ (the mean tangent modulus in $S_{1}$ ) and linear modulus $E_{2}$ (the mean tangent modulus in $S_{3}$ ) on strain rate is shown in Fig. 4a. It shows that the values of initial and linear moduli are of the magnitude of hundreds $P a$, and several $M P a$, respectively. Evolution of characteristic stages represented by the characteristic strain values $\varepsilon_{1}, \varepsilon_{2}$ and $\varepsilon_{3}$ as fractions of the ultimate strain $\varepsilon_{U T S}$ $\left(\frac{\varepsilon_{n}}{\varepsilon_{U T S}}, n=1,2,3\right)$ is given in Fig. $4 \mathrm{~b}$, that demonstrates also the extent of each stages. Also, values of stress for a certain strain levels $\left.\sigma\right|_{\varepsilon}$ and of the corresponding tangent modulus $\left.E\right|_{\varepsilon}$ at each strain rate were measured and are shown in Figs. $4 \mathrm{c}$ and d, respectively. All the values in Fig. 4 can be found in Table 1.

From the obtained values, the general character of evolution with increasing strain rate can be described as follows:

i. Values of initial and linear moduli of the studied BC hydrogel increased up to 0.0033 $\mathrm{s}^{-1}$ from $0.31 \pm 0.05$ and $2.72 \pm 0.40 \mathrm{MPa}$ at strain rate of $0.0001 \mathrm{~s}^{-1}$ to $0.61 \pm 0.07$ and $3.88 \pm 0.29 \mathrm{MPa}$ at strain rate of $0.0033 \mathrm{~s}^{-1}$, respectively, and then decreased to $0.20 \pm$ 0.05 and $1.16 \pm 0.21 \mathrm{MPa}$ at strain rate of $0.3 \mathrm{~s}^{-1}$, see Fig. $4 \mathrm{a}$.

ii. A slight increase of initial modulus was found: from $0.27 \pm 0.03 \mathrm{MPa}$ at strain rate of $0.033 \mathrm{~s}^{-1}$ to $0.29 \pm 0.05 \mathrm{MPa}$ at strain rate of $0.1 \mathrm{~s}^{-1}$ (Fig. 4a).

iii. The initial quasi-linear stage $\left(S_{1}\right)$ occupied some $10 \%$ of the whole process, and decreased at high strain rates. The non-linear stage $\left(S_{2}\right)$ occupied from around $45 \%$ to $60 \%$, and increased along with the increasing strain rate. The linear stage $\left(S_{3}\right)$ was equal to around $20 \% \sim 30 \%$ of the whole process, and decreased with strain rate. The 
pre-failure stage $\left(S_{4}\right)$ was around $10 \%$ of the entire process, without any significant fluctuations.

iv. Both the value of stress and the corresponding tangent modulus at all strain levels follow a dependence on the strain rate (changing from hardening to softening, with the peak at strain rate of $0.0033 \mathrm{~s}^{-1}$ ), similar to that of initial and linear moduli.
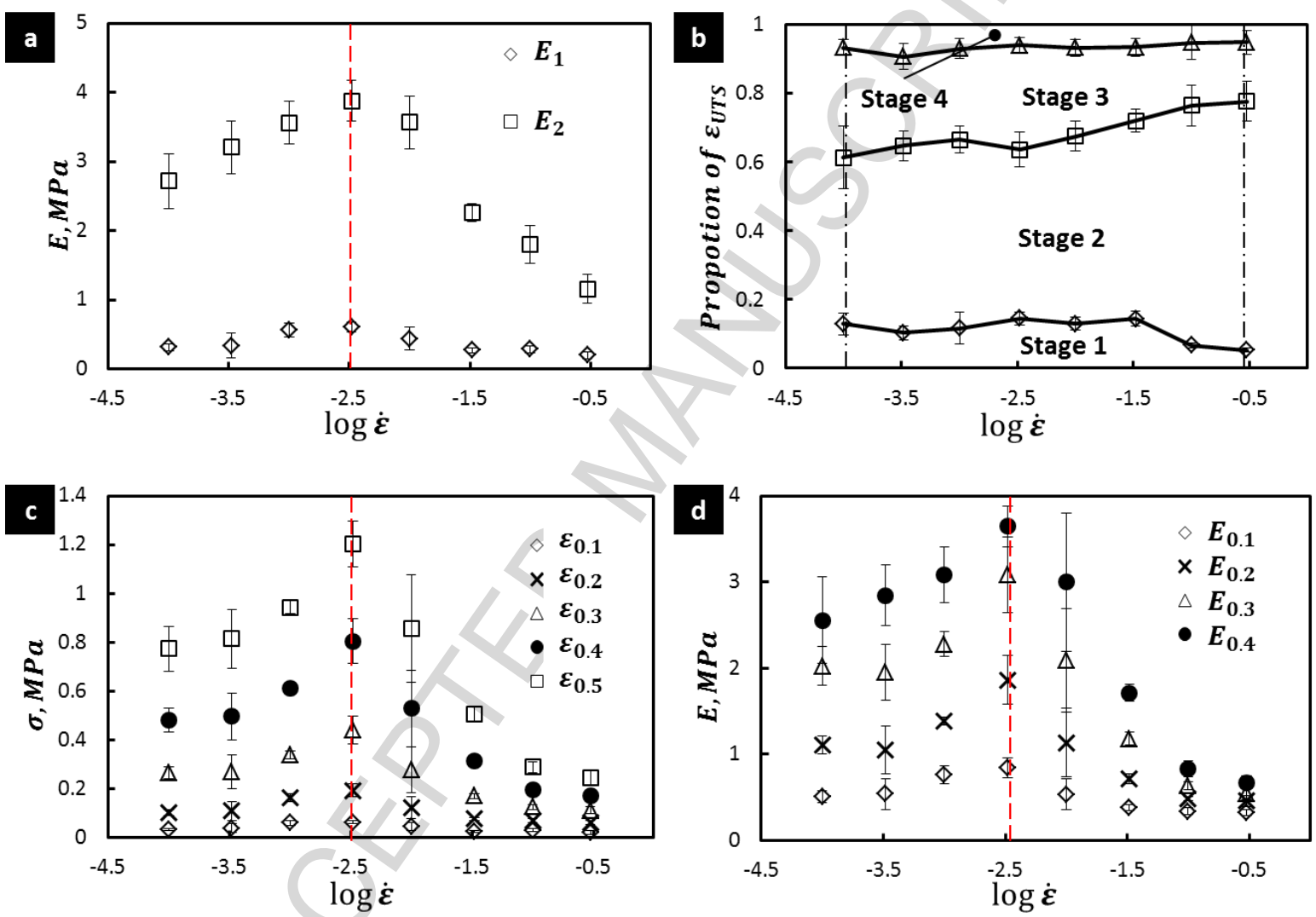

Figure 4: (a) Initial modulus $\boldsymbol{E}_{\mathbf{1}}$ and linear modulus $\boldsymbol{E}_{\mathbf{2}}$ for various strain rates. (b) Evolution of characteristic stages based on results of tensile behaviour for increased strain rate. Dependence of stress (c) and tangent modulus (d) on strain rate at certain strain levels 
Table 1: Values of characteristic mechanical parameters for each stage at various strain rates

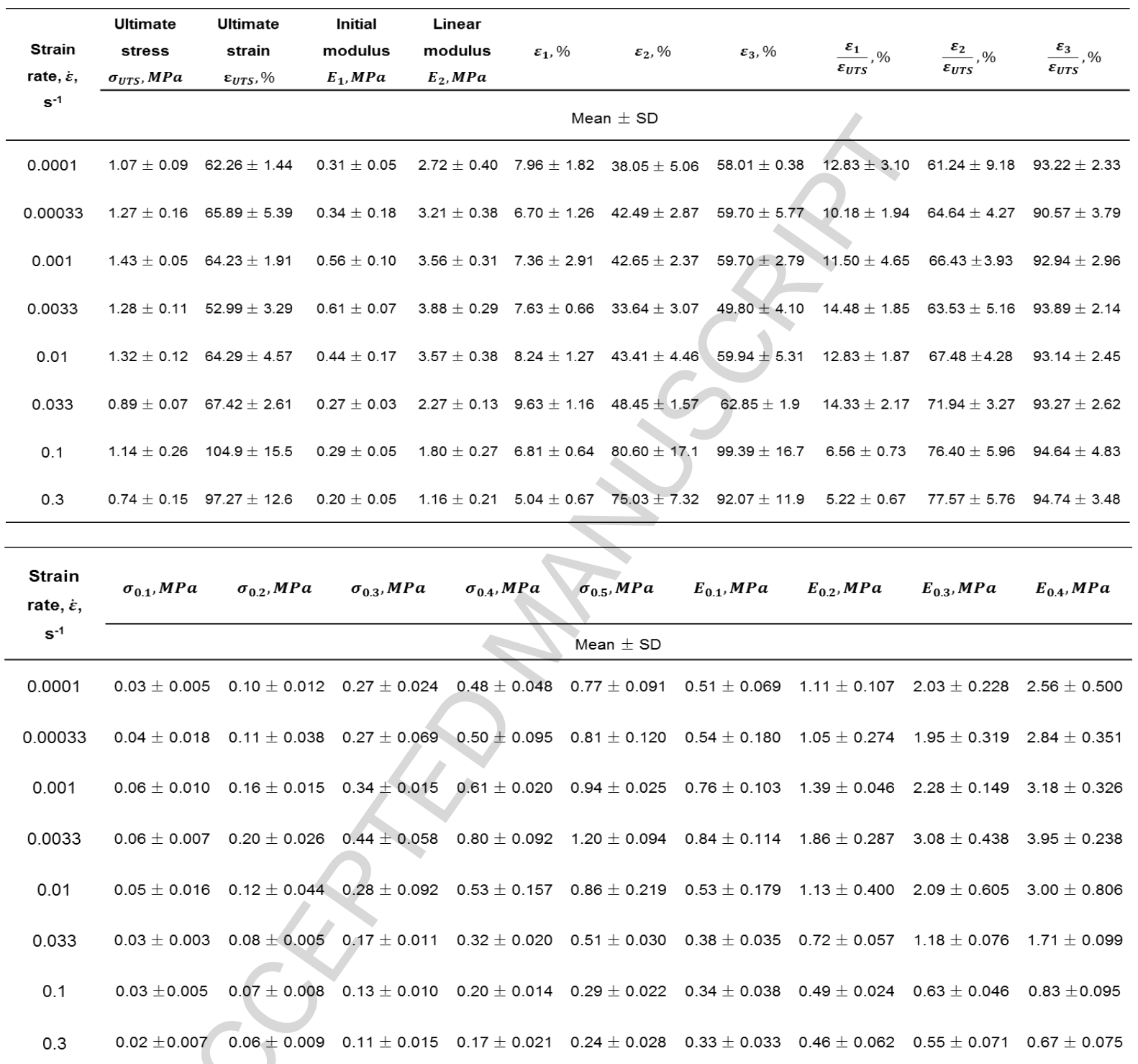

\subsection{Strain-rate-sensitivity}

From the early study by Alder and Philips, yield stress is related to the strain rate, and according to the definition of strain-rate sensitivity, at fixed strain, stress can be presented by [19]

$\sigma=\frac{F}{A}=K \dot{\varepsilon}^{m}$

where $F$ is the applied force, $A$ is the cross-sectional area of the specimen, $K$ is the material constant, $\dot{\varepsilon}$ is the strain rate, $m$ is the strain-rate-sensitivity exponent. The value of $m$ can be calculated from a log-log plot of the stresses at fixed plastic strain correlated with the strain rate [26], assessed by the following expression [27]: 
$m=\left.\frac{\Delta \log \sigma}{\Delta \log \dot{\varepsilon}}\right|_{\varepsilon}$

The strain-rate-sensitivity exponent $m$ at each strain was determined based on equation (2) using a linear least-square method. Variation of $m$ with the strain rate at strain levels from $10 \%$ to $50 \%$ was numerically calculated (see in Fig. 5). All the values of $m$ is less than 0.5 . A general process can be divided into a stage with positive $m$ followed by a stage with negative exponents, reflecting strain-rate-dependent hardening and softening, respectively, with a transition between the stages at strain rates between $0.001 \mathrm{~s}^{-1}$ and $0.003 \mathrm{~s}^{-1}$. The value of the exponent has a tendency approaching zero at both low and high strain rates, suggesting that the $\mathrm{BC}$ hydrogel might not be sensitive to the strain rate when applying a tensile load at strain rates outside the studied range from 0.0001 to $0.3 \mathrm{~s}^{-1}$.

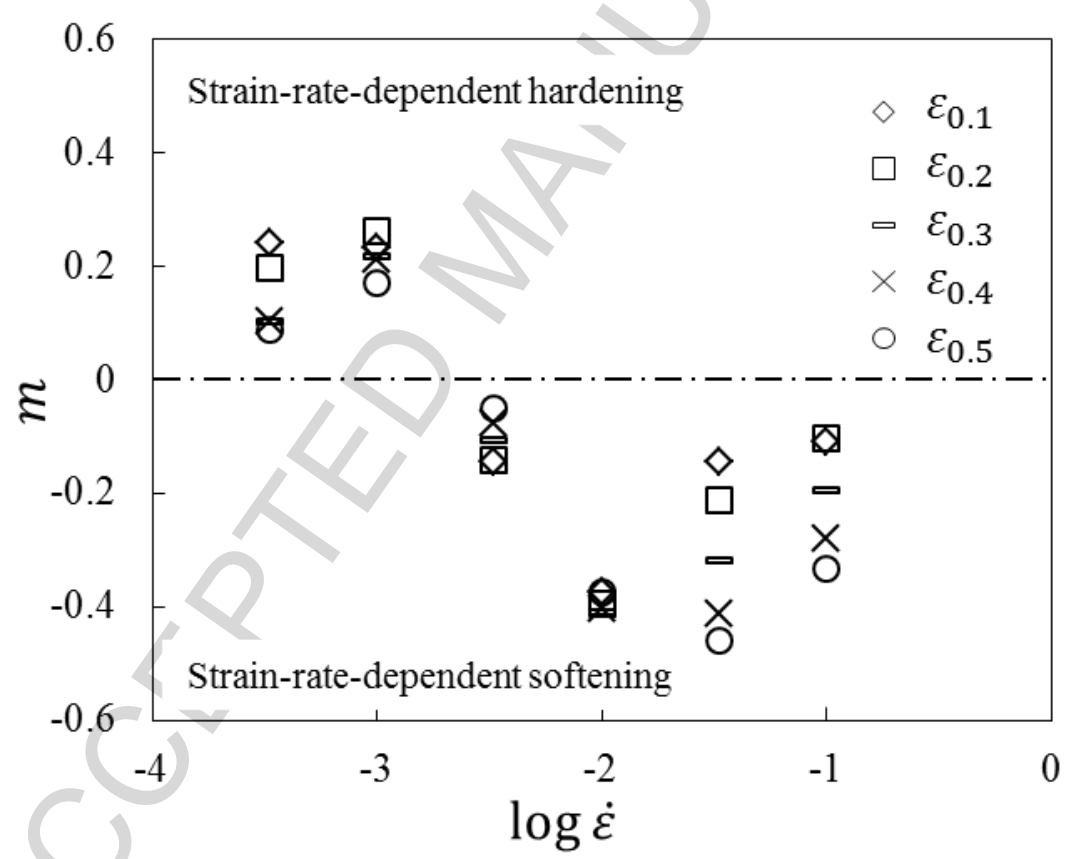

Figure 5: Evolution of the strain-rate-sensitivity exponent at various strain levels shows that the BC hydrogel demonstrates strain-rate-dependent behaviour changing from hardening to softening.

\subsection{Microstructural changes at various strain rates}

Under tension, fibre reorientation in fibrous plane is a main deformation mechanism leading to material stiffening [15]. Micro-morphology of specimen after 50\% stretching at low and high strain rates is shown in Figs. 6a and c, respectively. A general tendency could be formulated: more fibres were reoriented along the direction of induced loading at low strain rate. The data on fibre orientation was obtained with image processing, and then converted into a probability density distribution function, as shown in Figs. $6 \mathrm{~b}$ and d. Clearly, more fibres were aligned with the loading direction at low-strain-rate loading. 
Low strain-rate: $0.01 \% s^{-1}$
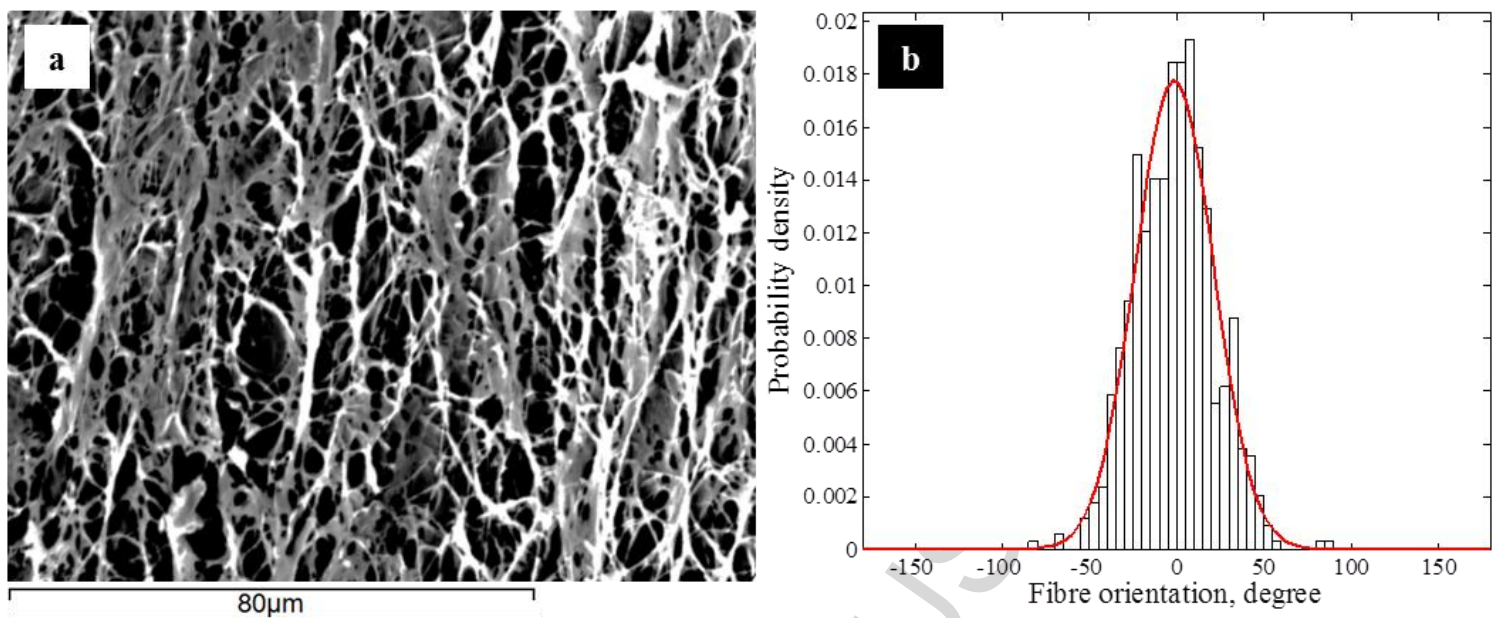

High strain-rate: $10 \% s^{-1}$
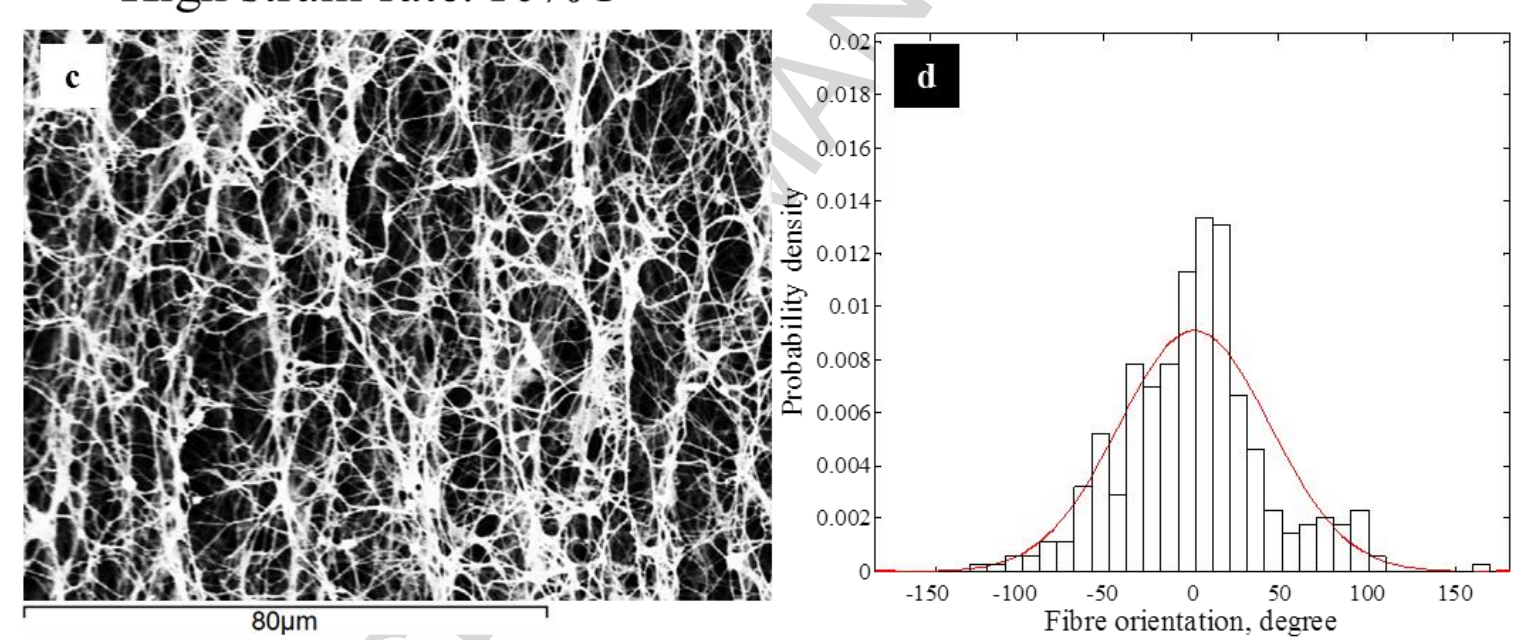

Figure 6: Micro-morphology of fibre distribution after 50\% stretching at low (a) and high (c) strain rates; probability density distribution of fibre orientation at low (b) and high (d) strain rates.

When applying an in-plane tensile load to stretch specimen, fibrous layers shrink, as a result pressing free water out. Cross-sectional images after tension at various strain rates are a key to determine the character of motion of free water. Micro-morphology of fibrous layers after deformations at low, medium and high strain rates after $40 \%$ stretching is observed (Fig. 7). Some conclusions can be formulated: (i) at low strain rates, a layered structure is obvious together with cross-links (Figs. 7 a and d). This morphology, in general, retains its initial features; (ii) at high strain rates (Figs. $7 \mathrm{c}$ and f), the morphology is more of a cellular structure with homogeneous regular and deep cells; (iii) at medium strain rates (Figs. $7 \mathrm{~b}$ and e), some elements of the cellular structure are apparent, but it is not as regular and the cells are not as deep as those at high strain rates; the fibrous layered structure can be still recognized. A tendency to form a cellular-like structure when increasing the strain rate is evidenced. In this way, the structure at medium strain rate can be considered as a result of an incomplete process compared to that at high strain rates. 
Low strain-rate: $0.01 \% \mathrm{~s}^{-1}$
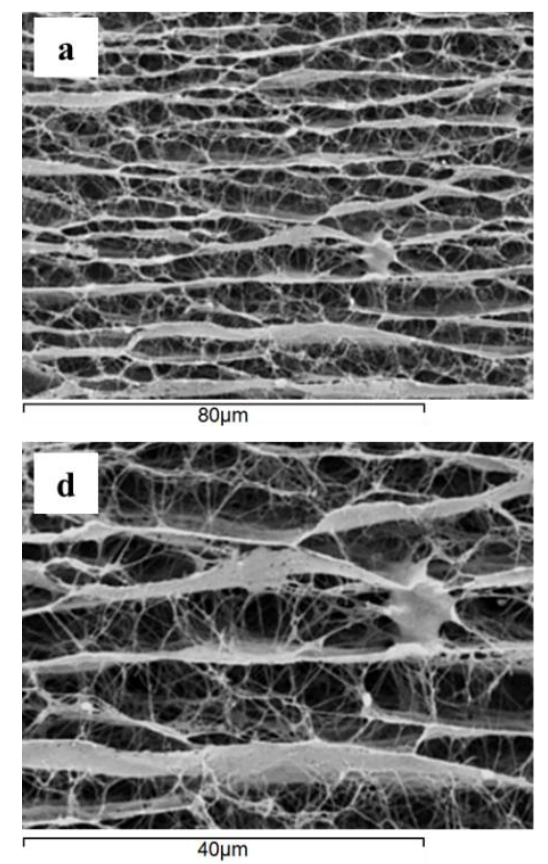

Medium strain-rate: $0.3 \% s^{-1}$
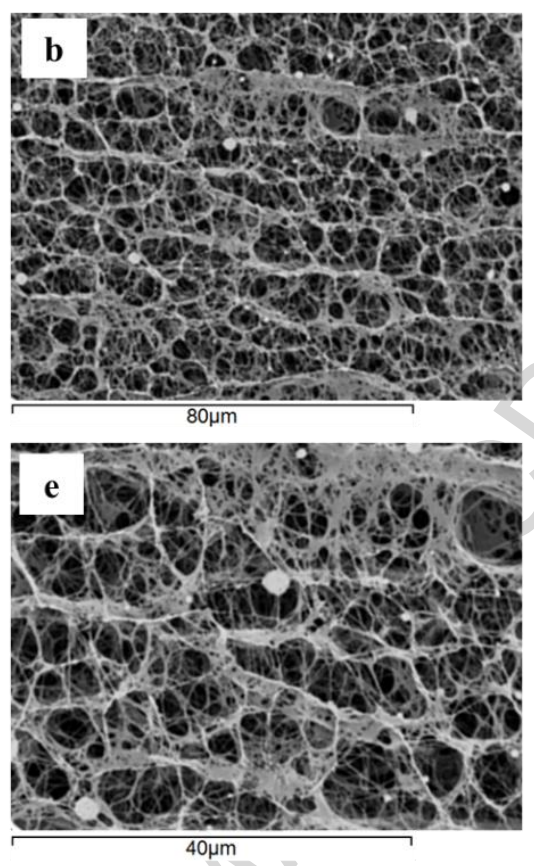

High strain-rate: $10 \% \mathrm{~s}^{-1}$
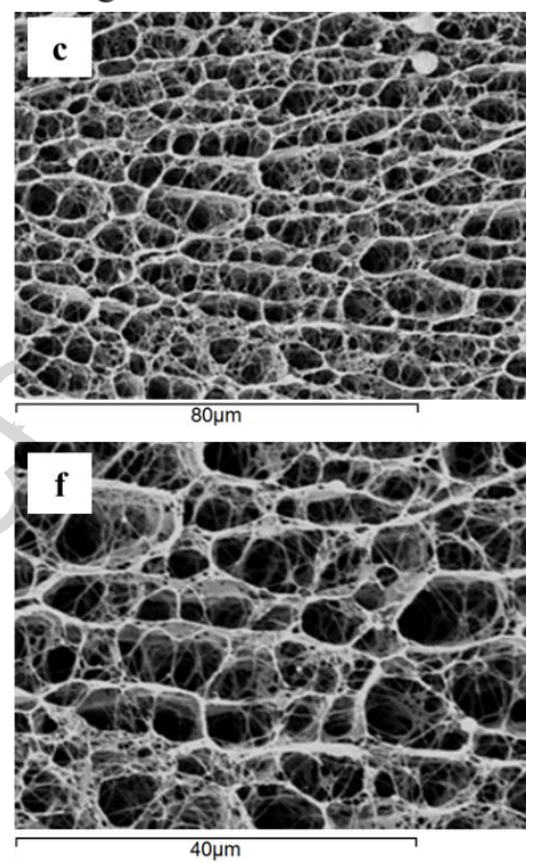

Figure 7: Cross-sectional morphology after $40 \%$ tensile stretching at strain rate of $0.01 \% \mathrm{~s}^{-1}$ (a and d), $0.3 \% \mathrm{~s}^{-1}\left(\mathrm{~b}\right.$ and $\mathrm{e}$ ) and $10 \% \mathrm{~s}^{-1}(\mathrm{c}$ and $\mathrm{f})$

\section{Discussions}

In this study, uniaxial tension at various strain rates ranging from $0.0001 \mathrm{~s}^{-1}$ to $0.3 \mathrm{~s}^{-1}$ was applied to the $\mathrm{BC}$ hydrogel to investigate its in-plane strain-rate-dependent behaviour. Evolution of its tangent modulus emphasizes four typical stages with regard to some specific parameters, such as initial modulus $E_{1}$ and linear modulus $E_{2}$. The dependences of those parameters on the strain rate reflect a process of transition from material hardening to softening (Figs. 4.a, c and d). Evolution of characteristic stages of this transition implies that processes at Stage 2 need a higher response time at high strain rates since the contribution of $S_{2}$ increased gradually with the increased strain rate at its high level (Fig. 4b).

Basically, viscoelastic materials demonstrate strain-rate-dependent behaviour. Most traditional viscoelastic materials are characterised by strain-rate hardening with a positive $m$; still, in some special cases, strain-rate softening was documented. As an example, Srivastava et al. [23] found that amorphous polymer Zeonex-690R exhibited strain-rate softening at large deformations at high strain rate $\left(0.3 \mathrm{~s}^{-1}\right)$, suggesting the effect of adiabatic heating (thermal softening). In the work of Canadinc et al. [28], negative strain-rate-sensitivity of Hadfield steel polycrystals was determined mainly due to dynamic strain aging (Portevin-Le Chatelier effect).

Such typical strain-rate hardening behaviour was observed mostly in continuous viscoelastic materials. The studied BC hydrogel could be generally regarded as a discontinuous material, with a large content of free water. The obtained results demonstrate that, at constant temperature, the $\mathrm{BC}$ hydrogel has anomalous strain-rate-sensitivity with a transition from 
hardening to softening. Unlike thermally induced strain-rate softening, heat dissipation from molecular chains in the $\mathrm{BC}$ would be absorbed imminently by a high content of water. In contrast to dynamic strain aging, dislocation movement is irrelevant to deformation processes in the $\mathrm{BC}$ hydrogel.

From the recorded images, a cross-sectional area after a defined deformation at high strain rates is larger than that at low strain rates (Fig. 2), implying that shrinkage of the nanofibre network is time-dependent. From the results in Fig. 4b, the tangent modulus in $S_{2}$ increased with increasing strain, as a result of fibre reorientation. $S_{2}$ had a longer duration at high strain rates, indicating that the fibre-reorientation process needed more time to respond to stretching at high strain rates. Moreover, based on the micro-morphological observations (Fig. 6), the following conclusion can be drawn: at high strain rate, due to the limited response time, the fibre-reorientation process is not fully completed, leading to material softening.

At the lowest studied strain rate of $0.0001 \mathrm{~s}^{-1}$, the shrinking process of the layered structure is extremely slow so that free water is almost in a static condition. Flow resistance in this condition is small and that layered structure remains practically the same, according to the observation (Fig. 7a, d). Water is almost free to move nearly in any direction between fibrous layers (Fig. 8a). At high strain rate of $0.1 \mathrm{~s}^{-1}$, flow resistance is relatively high. When shrinkage of fibrous layers occurs, free water attempts to prevent this process. As a result, side walls of cells were formed by the process of squeezing out water (Fig. 8b). Due to (i) incompressibility of water and (ii) a high loading rate, free water pushed cross-links to form side walls until pressure level of each side reach a balance, resulting in formation of homogeneous cells. Caused by the continuing shrinking of fibrous layers, parts of free water were eventually squeezed out. The formed system of deep cells is like a sewer resulting from the movement of free water through the BC hydrogel (Fig. 8b). Because of the high flow resistance, water movement prevents fibre reorientation, as discussed previously, leading to material softening.

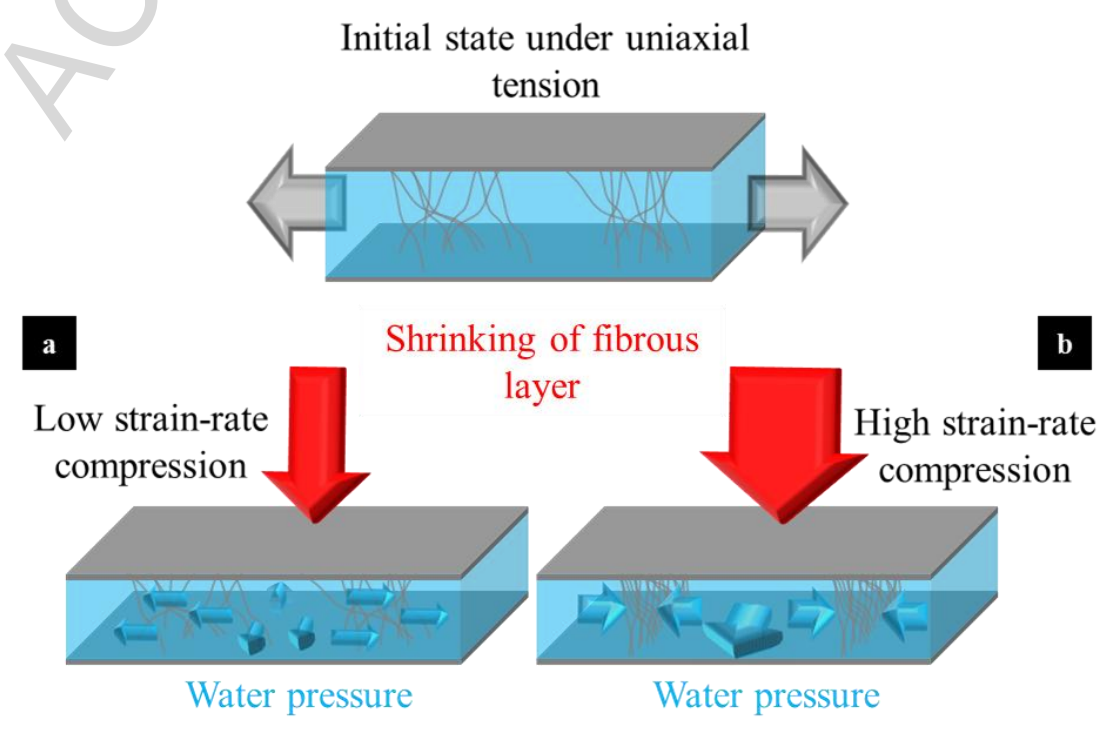

Figure 8: Schematic diagram of kinematic process of free-water movement under tension at low (a) and high (b) strain-rate level 


\section{Conclusions}

In-plane strain-rate-dependent behaviour of the $\mathrm{BC}$ hydrogel is assessed with in-aqua uniaxial tensile tests at various strain rates ranging from $0.0001 \mathrm{~s}^{-1}$ to $0.3 \mathrm{~s}^{-1}$. The obtained experimental results demonstrate anomalous strain-rate-dependent behaviour of the hydrogel with transition from insensitive to strain-rate, to strain-rate hardening followed by strain-rate softening and, once again, strain-rate insensitive. Micro-morphological observations showed microstructural changes at low and high strain rates as a result of realization of different deformation processes, suggesting that the main mechanisms responsible for strain-rate softening are reorientation of nanofibres and kinematics of free-water movement.

\section{Acknowledgement}

The authors would like to acknowledge the $7^{\text {th }}$ European Community Framework Programme for financial support through a Marie Curie International Research Staff Exchange Scheme (IRSES) Project entitled "Micro-Multi-Material Manufacture to Enable Multifunctional Miniaturised Devices (M6)" (Grant No. PIRSES-GA-2010-269113). Additional support from China-European Union technology cooperation programme (Grant No. 1110) is also acknowledged. 


\section{References}

[1] Shi, Z., Zhang, Y., Phillips, G. O., Yang, G., "Utilization of bacterial cellulose in food," Food Hydrocolloids, vol. 35, pp. 539-545, 2014.

[2] Fu, L., Zhang, Y., Li, C., Wu, Z., Zhuo, Q., Huang, X., Qiu, G., Zhou, P., Yang, G., "Skin tissue repair materials from bacterial celluose by a multiayer fementation method," $J$. Mater. Chem., vol. 22, no. 24, pp. 12349-12357, 2012.

[3] Fu, L., Zhou, P., Zhang, S., Yang, G., "Evaluation of bacterial nanocellulose-based uniform wound dressing for large area skin transplantation," Mater. Sci. Eng. C, vol. 33, pp. 2995-3000, 2013.

[4] Huang, L., Chen, X., Xuan, N.T., Tang, H., Zhang, L., Yang, G., "Nano-cellulose 3Dnetworks as controlled-release drug carriers," J. Mater. Chem. B, vol. 1, pp. 2976-2984, 2013.

[5] Malm, C.J., Risberg, B., Bodin, A., Backdahl, H., Johansson, B.R., Gatenholm, P., Jeppsson, A., "Small calibre biosynthetic bacterial cellulose blood vessels: 13-months patency in a sheep model," Scand. Cardiovasc. J., vol. 46, no. 1, pp. 57-62, 2012.

[6] Zang, S., Zhang, R., Chen, H., Lu, Y., Zhou, J., Chang, X., Liu, G., Wu, Z., Yang, G., "Investigation on artificial blood vessels prepared from bacterial cellulose," Mater. Sci. Eng. C, vol. 46, pp. 111-117, 2015.

[7] Kowalska-Ludwicka, K., Grobelski, B., Cala, J., Grobelski, B., Sygut, D., JesionekKupnicka, D., Kolodziejczyk, M., Bielecki, S., Pasieka, Z., "Special paper-New methods Modified bacterial cellulose tubes for regeneration of damaged peripheral nerves," Arch. Med. Sci., vol. 9, no. 3, pp. 527-534, 2013.

[8] Nimeskern, L., Avila, H.M., Sundberg, J., Gatenholm, P., Muller, R. and Stok, K.S., "Mechanical evaluation of bacterial nanocellulose as an implant material for ear cartilage replacement," J. Mech. Behav. Biomed. Mater., vol. 22, pp. 12-21, 2013.

[9] Wang, J., Gao, C., Zhang, Y., Wan, Y., "Preparation and in vitro characterization of BC/PVA hydrogel composite for its potential use as artificial cornea biomaterial," Mater. Sci. Eng. C, vol. 30, pp. 214-218, 2010.

[10] Buyanov, A.L., Gofman, I.V., Revel'skayaa, L.G., Khripunova, A.K., Tkachenkob, A.A., "Anisotropic swelling and mechanical behavior of composite bacterial cellulosepoly(acrylamide or acrylamide-sodium acrylate) hydrogels," J. Mech. Behav. Biomed. Mater., vol. 3, pp. 102-111, 2010.

[11] Backdahl, H., Esguerra, M., Delbro, D., Risberg, B., Gatenholm, P., "Engineering microporosity in bacterial cellulose scaffolds," J. Tissue Eng. Regen. Med., vol. 2, p. 320-330, 2008. 
[12] Guhados, G., Wan, W., Hutter. J.L., "Measurement of the Elastic Modulus of Single Bacterial Cellulose Fibers Using Atomic Force Microscopy," Langmuir, vol. 21, p. 66426646, 2005.

[13] Tanpichai, S., Quero, F., Nogi, M., Yano, H., Young, R.J., Lindstro $\square$ m, T., Sampson, W.W., Eichhorn, S.J., "Effective Young's Modulus of Bacterial and Microfibrillated Cellulose Fibrils in Fibrous Networks," Biomacromolecules, vol. 13, p. 1340-1349, 2012.

[14] Brown, E.E., Laborie, M.G., Zhang, J., "Glutaraldehyde treatment of bacterial cellulose/fibrin composites: impact on morphology, tensile and viscoelastic properties," Cellulose, vol. 19, pp. 127-137, 2012.

[15] Gao, X., Shi, Z., Liu, C., Yang, G., Sevostianov, I., Silberschmidt, V.V., "Inelastic behaviour of bacterial cellulose hydrogel:In aquacyclic tests," Polym. Test., vol. 44, pp. 82-92, 2015.

[16] Frensemeier, M., Koplin, C., Jaeger, R., Kramer, F., Klemm, D., "Mechanical Properties of Bacterially Synthesized Nanocellulose Hydrogels," Macromol. Symp., vol. 294, p. 38-44, 2010.

[17] Schiavi, A., Cuccaro, R., Troia, A., "Strain-rate and temperature dependent material properties of Agar and Gellan Gum used in biomedical applications," J. Mech. Behav. Biomed. Mater, vol. 53, pp. 119-130, 2016.

[18] Gao, X., Shi, Z., Kuśmierczyk, P., Liu, C., Yang, G., Sevostianov, I., Silberschmidt, V.V., "Time-dependent rheological behaviour of bacterial cellulose hydrogel," Mater. Sci. Eng. C, vol. 58, pp. 153-159, 2016.

[19] R. Hertzberg, Deformation and Fracture Mechanics of Engineering Materials, New York, Santa Barbara, London, Sydney, Toronto: John Wiley \& Sons, Inc., 1976.

[20] Gilat, A., Goldberg, R.K. \& Roberts, G.D., "Experimental study of strain-rate dependent behavior of carbon/epoxy composite," Compos. Sci. Technol., vol. 62, pp. 1469-1476, 2002.

[21] Siviour, C.R., Walley, S.M., Proud, W.G. \& Field, J.E., "The high strain rate compressive behaviour of polycarbonate and polyvinylidene difluoride," Polymer, vol. 46, pp. 12546-12555, 2005.

[22] Wang, Y.M. \& Ma, E., "Strain hardening, strain rate sensitivity, and ductility of nanostructured metals," Mater. Sci. Eng., A, Vols. 375-377, pp. 46-52, 2004.

[23] Srivastava, V., Chester, S.A., Ames, N.M. \& Anand, L., "A thermo-mechanicallycoupled large-deformation theory for amorphous polymers in a temperature range which spans their glass transition,” Int. J. Plast., vol. 26, pp. 1138-1182, 2010.

[24] Lopez-Sanchez, P., Rincon, M., Wang, D., Brulhart, S., Stokes, J.R., Gidley, M.J., "Micromechanics and Poroelasticity of Hydrated Cellulose Networks," Biomacromolecules, vol. 15, p. 2274-2284, 2014. 
[25] “ASTM D638-10, Standard Test Method for Tensile Properties of Plastics,” pp. 3-4, 2010.

[26] Katz, J.M., Buckner, I.S., "Characterization of strain rate sensitivity in pharmaceutical materials using indentation creep analysis," Int. J. Pharm., vol. 442, pp. 13-19, 2013.

[27] Luo, J., Li, M., Yu, W., Li, H., "The variation of strain rate sensitivity exponent and strain hardening exponent in isothermal compression of Ti-6Al-4V alloy," Mater. Design, vol. 31, pp. 741-748, 2010.

[28] Canadinc, D., Efstathiou, C. \& Sehitoglu, H., "On the negative strain rate sensitivity of Hadfield steel,” Scripta Mater., vol. 59, pp. 1103-1106, 2008.

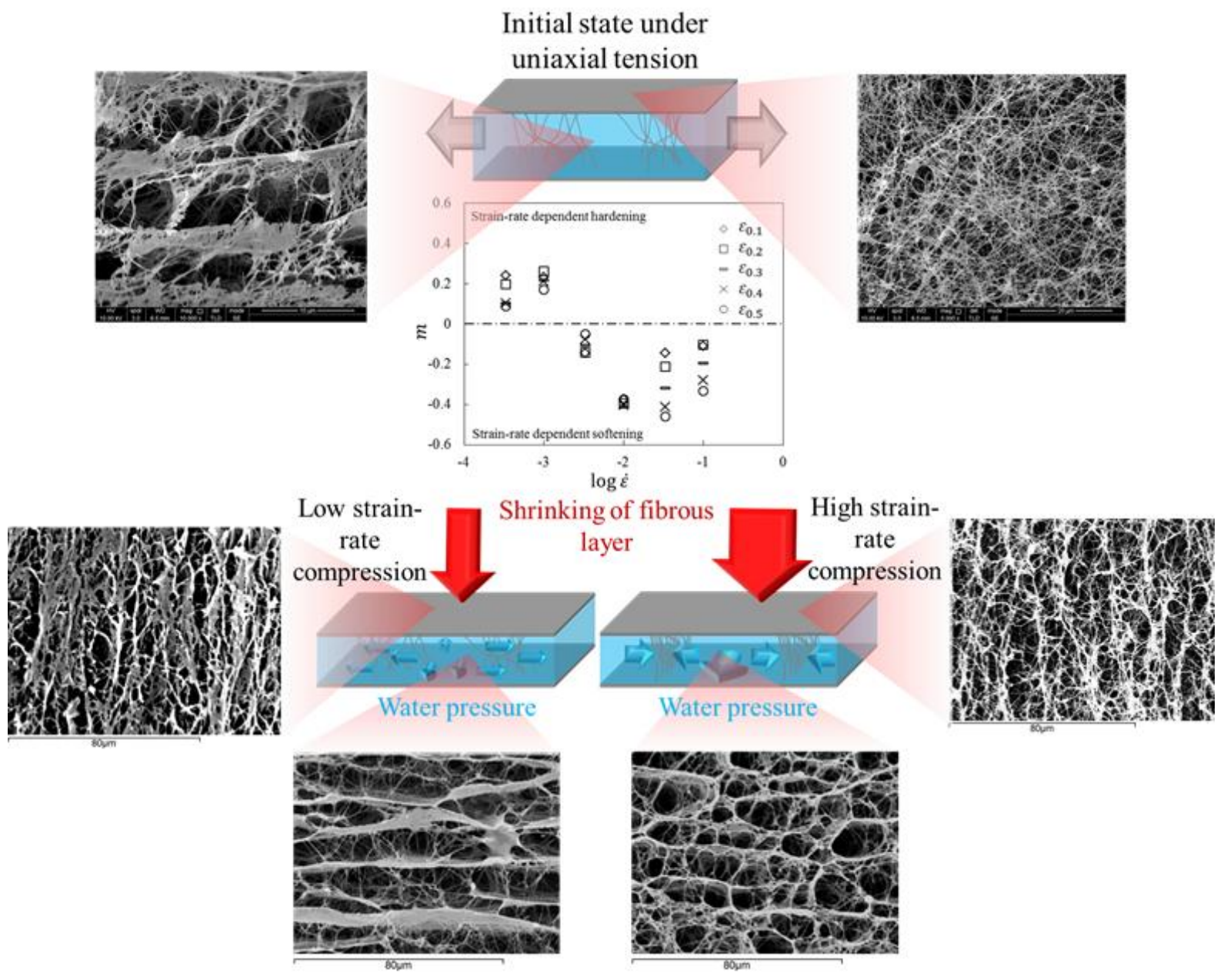

Graphical abstract 


\section{Highlights}

- Anomalous strain-rate-dependent behaviour - changing from insensitive to strain rate, hardening, softening, back to insensitive to strain rate - of bacterial cellulose hydrogel was characterised by performing uniaxial tensile tests at various strain rates ranging from $0.0001 \mathrm{~s}^{-1}$ to $0.3 \mathrm{~s}^{-1}$.

- Micro-morphological observations were carried out to determine microstructural changes in the process of deformation at low and high strain rates.

- Obtained results suggested that a fibre-reorientation process and kinematics of freewater movement play a dominant role in strain-rate softening behaviour. 